\title{
Moeda, Liquidez e Poupança Forçada na Economia Clássica*
}

\section{Money, Liquidity and Forced Saving in Classical Economics}

\author{
Sérgio Fornazier Meyrelles Filho** \\ Rogério Arthmar***
}

Resumo: Este artigo examina a concepção clássica sobre a moeda no contexto de conversibilidade do meio circulante. Para isso, inicia com uma revisão do modelo básico de determinação da oferta monetária ótima para os economistas clássicos, ressaltando a ideia de neutralidade da moeda e o processo de ajustamento dos mercados às variações no suprimento de metais preciosos, no curto e no longo prazo. A seguir, é realizada breve incursão nos debates monetários do século XIX na Inglaterra, explicitando os principais pontos de divergência entre as correntes de pensamento em confronto no que respeita à funcionalidade do padrão-ouro. Nos itens finais, são analisadas as diferentes instâncias de violação do princípio clássico de moeda neutra, particularmente a demanda por liquidez e a doutrina da poupança forçada.

Palavras-chave: Moeda. Liquidez. Poupança forçada.

Abstract: This paper examines the classical theory of money under a regime of convertible currency. It begins with a review of the classical model of the optimum monetary supply, stressing the idea of neutral money and also the markets' adjustment process to variations in the provision of precious metals in both the short and the long run. After that, a brief incursion into the monetary debates of nineteenth century England is conducted, making explicit the main divergent points among the contentious parties over the gold-standard functionality. In the end, the most important channels of violations of the classical postulate of neutral money are analyzed, specially the liquidity motive and the forced savings doctrine.

Keywords: Money. Liquidity. Forced saving.

JEL Classification: B12; B15; B30.

* O termo escola clássica é utilizado neste artigo em sentido lato, compreendendo os economistas situados no período entre as contribuições maiores de Smith (A Riqueza das Nações, 1776) e de Stuart Mill (Princípios de Economia Política, 1848). Tal delimitação, embora arbitrária, não exclui o reconhecimento de uma ortodoxia, representada por nomes como Ricardo, Say e McCulloch, partidários daquilo que Robbins denominou "Sistema de Liberdade Natural", no qual produtores e consumidores, agindo por interesse próprio, mas coagidos pela concorrência, promoveriam o bem-estar geral sob os auspícios da Lei dos Mercados e da Teoria Quantitativa da Moeda (ROBBINS, 1961, p. 11-33). De outra parte, o adjetivo clássico abrange igualmente os assim chamados dissidentes, como Lauderdale, Malthus e Sismondi, que, apesar de apontarem as falhas inerentes ao processo de acumulação de capital, acreditavam na teoria ricardiana do valor e no princípio smithiano de conversão automática da poupança em investimento. Muitos nomes de menor expressão, todavia, especialmente os envolvidos nos debates monetários da primeira metade do século XIX, são de difícil enquadramento sob qualquer ponto de vista, até mesmo por se ocuparem exclusivamente de questões práticas. Seja com for, a indicação dos mesmos como clássicos permite contextualizá-los na moldura maior dos debates da época. Sobre esse tópico, veja-se Sowell (1974, p. 3-32) e O`Brien (1975, p. 83-112).

** Professor adjunto de Economia da Universidade Federal de Goiás. E-mail: fornazier@face.ufg.br

*** Professor associado do Departamento de Economia da UFES. E-mail: arthmar.vix@gmail.com 


\section{Introdução}

O amplo campo de investigações dos economistas clássicos, numa conjuntura histórica de rápidas transformações no capitalismo industrial da Inglaterra no século XIX, ensejaria uma diversidade de posicionamentos sobre questões não só de cunho teórico, mas também de teor prático que, não raramente, pareciam conflitar entre si. Assim, por certo, ocorreu com a visão clássica sobre a moeda, identificada no mais das vezes com a proposição de neutralidade dos fenômenos monetários relativamente à economia real. Se, por um lado, essa leitura do pensamento clássico corresponde ao que a quase totalidade dos economistas ortodoxos da época e, até mesmo, alguns heterodoxos, assumiam, por outro, ela omite as exceções a esse princípio presentes nos escritos monetários dos autores mais representativos do período. ${ }^{1}$

O presente artigo busca analisar justamente esses dois aspectos da teoria clássica sobre a moeda, contemplando não apenas as elaborações mais abstratas como também aquelas ligadas à administração efetiva do meio circulante. Com tal propósito, apresenta-se, numa primeira parte, a abordagem da oferta monetária ótima num regime de conversibilidade ouro segundo as óticas de Hume, Smith, Ricardo e Stuart Mill. Na sequência, reconstituem-se, de forma resumida, as ideias centrais das correntes antagônicas nos debates sobre a moeda travados na primeira metade do século XIX na Inglaterra. No caso, as controvérsias relativas à emissão monetária e à regulação do sistema de padrão-ouro. Nas duas últimas seções, são revistas, por fim, as principais formas de transgressão da dicotomia clássica entre economia real e monetária admitidas pelos economistas da época. Mais especificamente, examinam-se os determinantes da procura pela liquidez e da poupança forçada, bem como as relações de tais conceitos com as teses estagnacionistas e as interpretações das crises comerciais propostas durante o período.

\section{A Teoria Monetária Clássica: O Modelo Básico}

Quando se menciona a teoria clássica em geral, poucos hesitarão em indicar os escritos de Adam Smith como ponto de partida obrigatório. O mesmo procedimento, certamente, aplica-se à teoria monetária dessa escola de pensamento. Embora tenha ela atingido, com David Ricardo, Henry Thornton e John Stuart Mill, entre outros, grau de sofisticação mais elevado que aquele presente na análise de Smith, é inegável que parte importante do que estava por vir já se encontrava anunciado nas páginas de A riqueza das nações (1776). De acordo com Hollander (1910, p. 429), "Aqui [a teoria da moeda], como em

1 Ressalte-se, no entanto, como aponta Niebyl (1948, p. 32-37), que a ênfase mercantilista no acúmulo de metais preciosos respondia, entre outros motivos (VINER, 1937, p. 15-51), às necessidades de financiamento da expansão manufatureira de capital numa etapa histórica em que o crédito encontrava-se ainda em fase rudimentar de desenvolvimento. 
tudo o mais, a exposição de Smith, embora parcial e limitada, prevaleceu sem discussão durante bom lapso de tempo". Como será visto adiante, no entanto, as perturbações monetárias do século XIX viriam alterar substancialmente esse quadro.

Smith, é sabido, constrói sua teoria apoiado num conceito particular de riqueza. Assim, ele a define desde logo como um conjunto heterogêneo de bens úteis e nos diz, além disso, que uma vez plenamente estabelecida a divisão do trabalho, a proporção das necessidades de um homem passíveis de serem atendidas com o produto de seu próprio esforço seria muito reduzida. Cada indivíduo, portanto, resultaria rico ou pobre na medida em que pudesse comandar trabalho alheio (SMITH, 1996, p. 87-100). O aspecto importante a ser retido a esse respeito é o de que a riqueza apresenta-se definida em termos reais, no que se tornaria um traço distintivo da análise clássica. Nesse sentido, seria errôneo e até mesmo falacioso, conclui Smith, identificar a riqueza com a posse de metais preciosos, como faziam os mercantilistas. Ora, diante dessa constatação, impunha-se de imediato perguntar então: qual, a rigor, o papel efetivo da moeda na economia?

Para Smith, a moeda consistiria, essencialmente, em meio facilitador do intercâmbio de bens, nascida da percepção dos inconvenientes associados ao escambo e dos obstáculos que ele representava para o progresso das trocas mercantis. A moeda, por conseguinte, jamais poderia ser confundida com o capital da sociedade, o qual estaria constituído pelos meios de produção disponíveis, concebidos em termos dos bens incorporáveis ao processo produtivo (SMITH, 1996, p. 352-356). Da mesma forma, a produção total de mercadorias e, logo, da riqueza, seria definida a partir de condicionantes estritamente reais, quais sejam, a quantidade de fatores de produção, o grau de divisão do trabalho e a intensidade da acumulação de capital. ${ }^{2}$ Outra variável determinada pela esfera real do sistema econômico, a taxa de juros, dependeria, por sua vez, do nível de lucratividade obtido pelo estoque de capital da economia.

A moeda, em tais condições, seria incapaz de exercer influência duradoura sobre quaisquer variáveis reais. Noutros termos, ela carregaria consigo a propriedade de ser neutra. Sob essa perspectiva, a expansão na oferta monetária poderia causar tão somente elevação do nível absoluto de preços, sem outros efeitos permanentes sobre o processo de geração de riqueza. $\mathrm{O}$ fragmento a seguir, quando Smith se põe a discorrer sobre eventual acréscimo na circulação dos metais preciosos, é representativo de sua concepção sobre o assunto:

Qualquer aumento da quantidade de prata, permanecendo idêntica a quantidade de mercadorias que fazia circular, não poderia ter outro efeito do que diminuir o valor desse metal. O valor nominal de todos os tipos de mercadorias seria maior, mas seu valor real seria exatamente o mesmo que antes. As mercadorias seriam trocadas por uma quantidade maior de

2 Como assinalam Corry (1962, p. 41) e Miglioli (1982, p. 52-53), a acumulação de capital, para os economistas clássicos, significava aumento do emprego da força de trabalho em atividades produtivas. Nesse sentido, as despesas de investimento acarretavam expansão automática no consumo dos trabalhadores, aspecto comumente negligenciado pelos economistas dissidentes como Malthus e Sismondi.

MEYRELLES FILHO, S. F.; ARTHMAR, R. Moeda, liquidez e poupança forçada na economia clássica. 
moedas de prata, mas a quantidade de trabalho que poderiam comandar e o número de pessoas às quais poderia dar emprego e manutenção seriam exatamente os mesmos. (SMITH, 1996, p. 353).

A ideia de neutralidade da moeda em relação à economia real seria aceita, a princípio, por todos os autores clássicos ortodoxos subsequentes, conforme ilustra Ricardo, por exemplo, na seguinte passagem:

Depois de se estabelecer um papel moeda devidamente regulamentado, o capital não pode aumentar, nem diminuir, com as operações bancárias. Então, se coubesse ao estado o poder de emitir papel moeda, embora nunca descontasse uma letra ou emprestasse um xelim ao público, não aconteceria alteração alguma no montante dos negócios, pois teríamos a mesma quantidade de matérias-primas, máquinas, produtos alimentícios e navios. (RICARDO, 1996, p. 268).

Ou, ainda, como reafirmaria mais tarde Stuart Mill em seus Princípios de Economia Política (1848):

Deve ser evidente, porém que a simples introdução de um sistema específico de trocar coisas umas pelas outras, trocando primeiro a coisa por dinheiro, e só então trocando o dinheiro por alguma outra coisa, não acarreta nenhuma diferença para a natureza básica das transações [...]. A introdução do dinheiro não interfere na operação de nenhuma das leis reguladoras do valor. (MILL, 1996, p. 63-64).

Os trechos anteriormente reproduzidos deixam transparecer nitidamente a concordância dos autores com a dicotomia entre as esferas real e monetária da economia. Fica evidente, do mesmo modo, a utilização da lógica subjacente à Teoria Quantitativa da Moeda. Essa concepção, cujas origens são anteriores aos escritos clássicos, remontando a Serra (1613), Locke (1692), Boudin (1756) e outros (NIEBYL, 1948, p. 29-52; HEGELAND, 1969, p. 26-46), estabelecia que o valor da moeda deveria variar inversamente à sua quantidade, dados sua respectiva velocidade de circulação e o volume de produção. Jean-Baptiste Say, no Tratado de Economia Política (1803), ao comentar o emprego dos diferentes metais como numerário, assegura: "Seu valor é sempre proporcional à quantidade de moeda que se põe em circulação, comparada com a quantidade que a circulação requer. Se as necessidades da circulação não aumentam e se aumenta o número de unidades monetárias, seu valor diminui" (SAY, 1983, p. 222).

Os economistas clássicos, de maneira geral, aceitavam a Teoria Quantitativa como um pressuposto fora de questionamento, embora aplicável apenas a situações de curto prazo. A posição defendida por Ricardo e Stuart Mill, por exemplo, era de que o valor da moeda seria determinado temporariamente pelas forças da oferta e demanda e, permanentemente, pelo custo de produção dos metais preciosos. Em outras palavras, no curto prazo prevaleceria a Teoria Quantitativa da Moeda, segundo a qual os preços deveriam flutuar de modo a conciliar o fluxo de dinheiro a ser gasto com o fluxo de bens e serviços a serem 
vendidos. No longo prazo, porém, prevaleceria a lei fundamental do valor, tal como interpretada por Ricardo, segundo a qual o valor de qualquer mercadoria, inclusive dos metais preciosos, estaria determinado pela quantidade de trabalho necessário à sua produção, abrangendo aí o custo médio da exploração aurífera compatível com lucros normais (LAIDLER, 1991, p. 8-19).

Detalhando um pouco mais, e seguindo o Gráfico 1 (ROCKOFF, 1984, p. 616), dada a cotação legal da unidade monetária em termos de ouro $p^{*}$ para um país produtor do metal, o respectivo poder de compra do dinheiro estaria fixado pelo nível geral de preços $p$ associado às curvas de demanda $D$ e de oferta $S$ por ouro. A demanda seria negativamente inclinada em vista de um nível de preços mais elevado implicar maior necessidade de ouro para financiar a circulação de um mesmo conjunto de bens. Já a oferta de curto prazo Sc seria positivamente inclinada devido ao custo marginal crescente de extração do metal, em face da tecnologia utilizada nas minas em operação, e à existência de estoques de ouro para uso industrial e ornamental. Assim, verificando-se um nível de preços relativamente baixo, como em A, ocorreria um equilíbrio entre a oferta de curto prazo $S c$ ' e demanda por ouro, de maneira que o poder de compra do metal estaria estabelecido por $p^{*} / p^{\prime}$. Nessa situação, porém, a mineração apresentaria alta lucratividade. Logo, novas minas seriam prospectadas, inovações na extração surgiriam e a curva de oferta terminaria por se deslocar progressivamente para a direita até alcançar Sc", fazendo por elevar o nível de preços e rebaixar o poder de compra do ouro até esse último coincidir com o valor determinado pela oferta de longo prazo $\mathrm{Sl}$. No equilíbrio final $B$ prevaleceria então taxa de retorno na exploração aurífera equivalente às demais aplicações do capital na economia (para uma análise dinâmica do modelo, consulte-se BARRO, 1985).

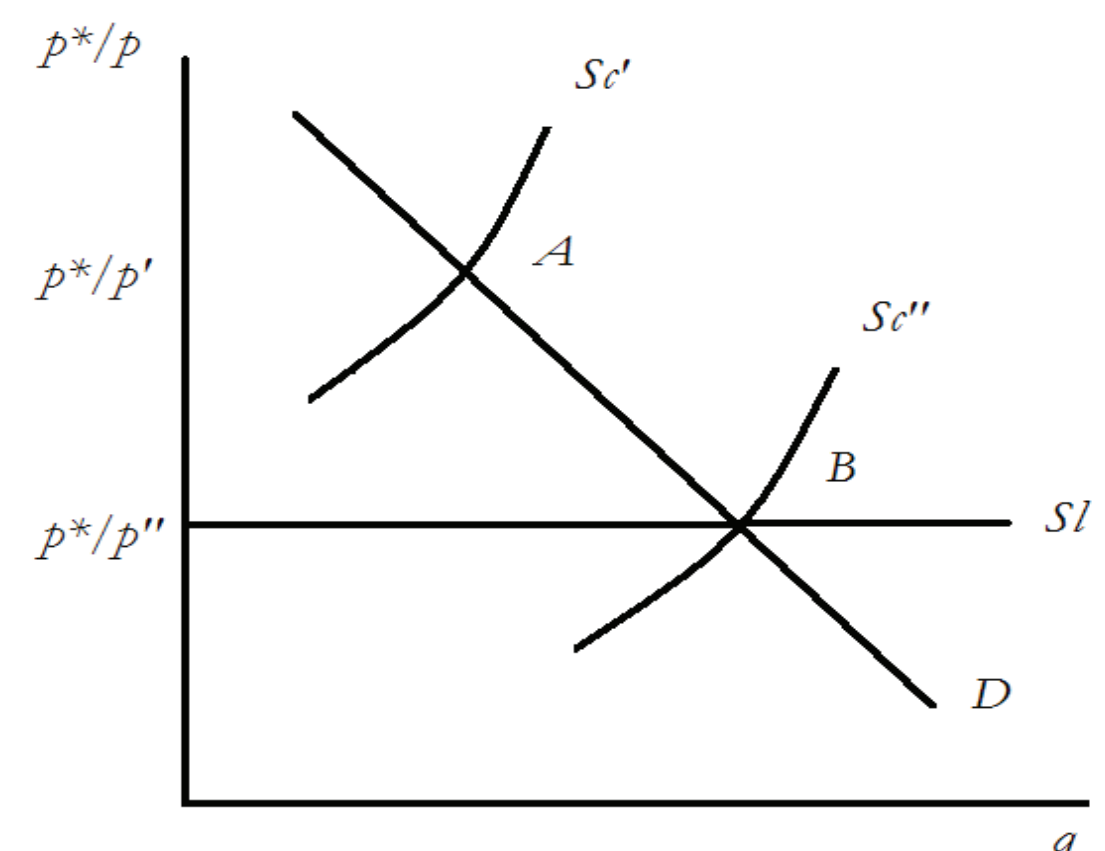

Gráfico 1 - A versão clássica do mercado de ouro monetário Fonte: Rockoff (1984). 
No contexto de uma economia aberta vinculada ao sistema internacional de padrão-ouro e sujeita a um eventual excesso de moeda, entraria em ação o mecanismo denominado price specie-flow, descrito originalmente por David Hume no ensaio Of the balance of trade (1752). Perante um aumento qualquer na oferta monetária, resultaria, segundo Hume, majoração mais ou menos automática dos preços internos. Se os preços no exterior permanecessem constantes (ou aumentassem a uma taxa inferior à dos preços domésticos), resultaria perda de competitividade da produção local nos mercados internacionais. Em outras palavras, haveria aumento das importações e diminuição das exportações do país. O consequente saldo desfavorável no comércio internacional conduziria, por sua vez, à transferência de metais preciosos ao exterior. À medida que isso acontecesse, a oferta monetária doméstica e, por decorrência, o nível interno de preços, seriam paulatinamente reduzidos até que se alcançasse nova posição de equilíbrio nas contas externas compatível com o nivelamento dos preços internacionais (considerando-se os custos de transporte). Na formulação de Hume:

Agora, suponha que todo o dinheiro da Grã-Bretanha se multiplicasse por cinco numa noite. [...] Não iriam nosso trabalho e mercadorias aumentar a um patamar exorbitante de sorte que nenhuma de nossas nações vizinhas poderia comprar de nós, enquanto as mercadorias delas, de outra parte, tornar-se-iam tão baratas que, a despeito de todas as leis que pudessem ser editadas, elas se colocariam em posição de superioridade em relação a nós, e nosso dinheiro escoaria para fora, até nos nivelarmos com os estrangeiros [...]? (HUME, 1985, p. 311).

É interessante observar aqui que Smith, ao tratar das questões relativas à possibilidade de um excesso de meio circulante na economia, não chegou a fazer uso da ideia do price-specie-flow. Segundo ele, na hipótese de uma oferta adicional de moeda, entraria em ação um mecanismo corretivo, o qual, contudo, independeria do sistema de preços. De acordo com sua interpretação, o elemento-chave para explicar a superação do desequilíbrio seria o conceito de redundância. Na visão de Smith, o ajustamento procederia de forma semelhante, tanto no caso da moeda metálica quanto no de papel-moeda, pois o total da moeda fiduciária requerida por um país não poderia jamais ultrapassar o valor do ouro e da prata em circulação se a mesma não existisse (SMITH, 1996, p. 300311). Caso o montante de papel-moeda extravasasse aquela soma, os agentes perceberiam um excesso de dinheiro em relação às suas necessidades de troca e, imediatamente, acorreriam aos bancos para converter suas notas bancárias em espécie. Efetivada a conversão, eles utilizariam o ouro e a prata para realizar compras no exterior, ocasionando, portanto, transferência de metais preciosos para fora do país e inevitável redução da quantidade de moeda em circulação: 
Sendo exatamente os mesmos que antes os bens a serem comprados e vendidos, será suficiente a mesma quantidade de dinheiro para comprálos e vendê-los. O canal de circulação [...] permanecerá o mesmo que antes. Supusemos que 1 milhão é suficiente para encher o canal. Tudo que, portanto, seja lançado no canal, além dessa soma, não poderá deslizar nele, vindo a transbordar. (SMITH, 1996, p. 302).

Essa análise de Smith constitui a base de sua concepção monetária conhecida por real bills doctrine, cuja proposição central, na definição de Mints (1945, p. 9), apoiava-se na premissa de que se somente "[...] notas 'reais' são descontadas, a expansão do dinheiro bancário será proporcional a qualquer extensão do comércio que tenha lugar e que, quando o comércio recua, os empréstimos bancários são correspondentemente resgatados". Smith, mais alegórico, assim resume seu ponto de vista: "Os cofres dos bancos [...] assemelham-se a um reservatório d'água, do qual, embora continuamente saia uma corrente, outra corrente continuamente entra, perfeitamente igual a que sai, de modo que o reservatório [...] mantém sempre um nível igual" (SMITH, 1996, p. 311). A atratividade desse tipo de raciocínio para os teóricos ligados ao sistema bancário durante os debates monetários do século XIX, como será visto adiante, residia no argumento de que se fossem concedidos unicamente empréstimos lastreados em sólidas garantias comerciais, a moeda disporia da elasticidade reclamada pelos negócios sem comprometimento da liquidez dos bancos.

Prosseguindo, então, é válido nesse momento levantar-se uma indagação suplementar no tocante à teoria monetária clássica, a saber: quais instrumentos, afinal, deveriam ser considerados moeda? Ou, ainda, o crédito, em suas várias formas, faria parte da oferta monetária? A resposta, em verdade, não é unívoca, pois havia, com efeito, larga diferença de pontos de vista em torno dessas questões. Os autores clássicos, no entanto, em sua maior parte, optaram por estabelecer uma distinção entre moeda e meio circulante. No primeiro conceito estariam incluídas as moedas metálicas e, eventualmente, as notas bancárias. Os papéis de crédito, em geral, comporiam, ao lado da moeda, o conjunto mais amplo denominado meio circulante. Estabelecida essa distinção, porém, existiam duas formas de encará-la. Poder-se-ia transformá-la em uma questão com desdobramentos analíticos cruciais, em nível da teoria e da formulação da política monetária, como fizeram os membros da chamada banking school, ou, então, tratá-la como uma distinção meramente semântica, sem repercussões fundamentais para a análise monetária. Essa última via parece ter sido aquela seguida por autores como Thornton e Stuart Mill, dentre outros expoentes do pensamento clássico dominante (LAIDLER, 1991, p. 13-16). 
A partir das ideias apresentadas, estamos agora em condições de delinear, como primeira aproximação, o que poderia ser chamado o modelo monetário básico utilizado pelos economistas clássicos. No quadro dessa construção teórica, a moeda seria apenas instrumento facilitador das trocas, incapaz de afetar as variáveis reais da economia de forma permanente. Seu valor seria determinado, no curto prazo, pela Teoria Quantitativa e, no longo prazo, pela lei geral do valor, isto é, por seu custo de produção em termos de trabalho. Haveria, igualmente, uma quantidade ótima de moeda no sistema econômico, garantida pela lei do valor atuando, de uma parte, via produção de ouro e, de outra, pela operação desimpedida do comércio internacional. Eventuais excessos seriam corrigidos (verificando-se a conversibilidade das diferentes moedas nacionais) pela ação do price specie-flow de Hume ou, então, pelo refluxo da moeda supérflua aos bancos, como indicado por Smith.

\section{Os Debates Monetários do Século XIX}

O desenvolvimento do pensamento clássico sobre a moeda não pode, em verdade, ser dissociado dos eventos monetários da época e, sobretudo, dos debates por eles suscitados na primeira metade do século XIX. Como bem indicou Sowell (1974, p. 64-66), controvérsias puramente abstratas no campo monetário não se apresentavam como algo característico da economia clássica, embora pudessem ocorrer, em escala considerável, em outras áreas, como na teoria do valor, por exemplo. Assim, para entendimento mais satisfatório da evolução do pensamento clássico sobre a moeda, convém proceder-se a uma breve recuperação do ambiente histórico em meio ao qual ele tomou corpo.

Em 27 de fevereiro de 1797, o Banco da Inglaterra, diante de extraordinária drenagem de suas reservas motivada por eventos relacionados à guerra com a França iniciada em 1793, suspendia o pagamento de suas notas em metais preciosos. Abandonava-se, assim, o marco da conversibilidade em favor de uma moeda fiduciária, situação que perduraria até o ano de 1821. Durante os anos de conflito, os ingleses tiveram que conviver com inflação crescente e constante deterioração do câmbio (para descrição e análise minuciosa dos acontecimentos da época, veja-se FETTER, 1965, p. 26-63; MINTS, 1945, p. 4260; VINER, 1937, p. 119-165). Esses eventos encontrariam tanto o público em geral quanto os economistas contemporâneos despreparados para apresentar um diagnóstico e propor soluções rápidas para os distúrbios monetários que se sucediam. A teoria econômica de então se limitava unicamente ao marco estrito da conversibilidade em ouro. Smith, ainda a maior autoridade ao início daquele século, referira-se, em $A$ riqueza das nações, somente de passagem à moeda inconversível, criticando o governo da Pensilvânia por obrigar a circulação de seus títulos como moeda corrente sem qualquer desconto ou lastro (SMITH, 1996, p. 330-332). Fazia-se urgente, em vista da situação, um refinamento, um passo adiante da teoria econômica rumo à compreensão dos efeitos associados à inconversibilidade. 
Assim de fato ocorreu, e as duas décadas que se seguiram à de 1790 foram marcadas por intensa controvérsia sobre temas monetários, dentro e fora do Parlamento inglês, em meio a qual surgiria profusa literatura relacionada ao assunto (FETTER, 1965, p. 26-95; HOLLANDER, 1910, p. 8-26). A disputa ficaria conhecida na história do pensamento econômico como o bullion debate. No bojo desse processo, a teoria monetária clássica avançaria na análise não apenas dos aspectos relacionados à transição de uma economia com dinheiro estritamente metálico para uma situação em que ele assumisse curso forçado, mas também na compreensão das perturbações monetárias de curto prazo associadas a tais transformações.

Os participantes do bullion debate dividiam-se, grosso modo, em dois campos opostos, os bulionistas e os antibulionistas, embora se possa argumentar que tal divisão não seja totalmente satisfatória. A posição bulionista, que representava a ortodoxia monetária clássica, pode ser resumida no seguinte enunciado: num contexto inflacionário, o surgimento de um prêmio sobre os metais preciosos e a depreciação cambial seriam, em última instância, os sinais mais conspícuos de que papel-moeda inconversível teria sido emitido em excesso. $\mathrm{Na}$ verdade, os bulionistas não constituíam um grupo tão homogêneo como se poderia pensar. Assim, é útil a distinção analítica sugerida por O’Brien (1975, p. 209-215) entre os bulionistas estritos e os moderados. No primeiro grupo estariam nomes como Walter Boyd, John Wheatley, Lord King e David Ricardo. Esses autores faziam uso bastante rigoroso, mesmo radical, da Teoria Quantitativa da Moeda. ${ }^{3}$ Tinham eles como princípio básico a ideia de que, para cada circunstância econômica, fosse de curto ou de longo prazo, haveria uma única quantidade ótima de moeda. Já entre os moderados encontramos Thomas Malthus e os signatários do célebre Bullion Report (1810), ${ }^{4}$ William Huskisson, Francis Horner e Henry Thornton. De acordo com essa vertente, apesar de o elevado preço dos metais, a depreciação do câmbio e a inflação representarem, no longo prazo, os melhores indicadores de emissão exagerada de papel-moeda, seria necessária análise mais sutil de determinadas variáveis como, por exemplo, a velocidade de circulação da moeda, a qual não poderia ser considerada constante. Sob essa perspectiva, era essencial a noção de que, no curto prazo, não existiria uma única quantidade ótima de moeda na economia e independente do estado de confiança dos agentes econômicos.

3 Segundo Sayers (1953, p. 34-37), a adesão incondicional de Ricardo à versão mais rigorosa da Teoria Quantitativa à época deveu-se, primeiramente, à grande depreciação da moeda irlandesa frente à libra, sucedida em 1802-1804 e motivada pela emissão excessiva de notas bancárias na Irlanda. Ademais, preocupava-lhe também a inoperância dos movimentos em espécie para reduzir os preços domésticos e expandir as exportações como forma de compensar os déficits comerciais causados pela guerra, o que deveria ter acontecido caso as teses antibulionistas estivessem corretas.

4 O Bullion Report resultou dos trabalhos do Bullion Committee, criado em fevereiro de 1810 pelo Parlamento britânico para analisar o impacto da política monetária e de outros eventos sobre as cotações da moeda inglesa. 
Para os antibulionistas, por sua vez, dentre eles John Sinclair, John Hill e Thomas Smith, a inflação deveria ser atribuída predominantemente a fenômenos reais e não a fatores monetários. O prêmio sobre o ouro e a depreciação cambial, por conseguinte, seriam decorrentes das pesadas transferências de recursos ao exterior realizadas em virtude da guerra e das importações adicionais decorrentes das más colheitas da época. Regra geral, os antibulionistas sustentavam que, quando as notas bancárias fossem emitidas apoiadas em letras de câmbio correspondentes a transações efetivas de bens e serviços, elas não poderiam ser qualificadas excessivas. Essa proposição, como visto, descendia diretamente, embora com ajustes à realidade do período, da real bills doctrine de Smith. Em relação a tal argumento, os bulionistas retrucavam colocando em dúvida a capacidade de o sistema bancário distinguir entre as letras de câmbio que tinham e as que não tinham, efetivamente, correspondência na produção. ${ }^{5}$

O embate entre os dois campos prolongar-se-ia até 1821, quando finalmente seria retomada a conversibilidade em espécie da libra esterlina. Aqueles, todavia, que julgavam o retorno às regras do padrão-ouro condição suficiente para o equilíbrio do sistema monetário do reino veriam suas esperanças ruírem diante de uma série de crises financeiras e comerciais durante as duas décadas seguintes. ${ }^{6}$ À medida que os abalos monetários se sucediam e tinha lugar célere proliferação dos joint-stock banks pelo país, multiplicavam-se as vozes reclamando a criação de instrumentos destinados a garantir o correto funcionamento do sistema e a preservar o lastro em ouro da moeda. Estava configurado o palco para nova controvérsia na arena monetária, a se desenrolar entre 1836 e 1845. Nesse debate, mais uma vez, distinguiam-se duas posições antagônicas. De um lado, a currency school, representada por nomes como George Norman (um dos diretores do Banco da Inglaterra) e Lord Overstone, que defendiam a posição quantitativista extrema. De outro, a banking school, cujos principais expoentes eram Thomas Tooke, John Fullarton e James Wilson, reeditando, de certa forma, o argumento smithiano das real bills. Ambos os lados, entretanto, sustentavam que a preservação da conversibilidade do papelmoeda constituía-se matéria indiscutível.

5 Smith, como mencionado, defendia que a quantidade de papel-moeda capaz de ser absorvida em um país não poderia ultrapassar o valor dos metais preciosos que circulariam na ausência da mesma. A condição básica para o equilíbrio do sistema, porém, seria a plena conversibilidade. Essa premissa deixa de existir quando os antibulionistas passam a transpor o esquema analítico de Smith para um contexto de inconversibilidade (ANDRADE; LOPES, 1989, p. 74-75).

6 Conforme Hyndman (1967), o século XIX na Inglaterra registraria a seguinte cronologia de crises comerciais e financeiras: (i) 1825, após uma onda de empréstimos de risco a governos da América do Sul; (ii) 1836-39, associada à falência de centenas de bancos norte-americanos sulistas com intensa participação de capitais britânicos; (iii) 1847, ao término da febre de construção ferroviária financiada pelos bancos do país; (iv) 1857, com o fim dos efeitos inflacionários das descobertas de ouro na Califórnia e Austrália; (v) 1866, após a falência do banco Overend, Gurney $\mathcal{E}$ Co., um dos maiores do país; (vi) 1873, crise financeira iniciada em Viena e propagada pela Europa e Estados Unidos; (vii) 1882, falência do banco francês Union Générale, com forte repercussão na Inglaterra; e, por fim, (viii) 1890, colapso do banco Barings devido à insolvência da Argentina. 

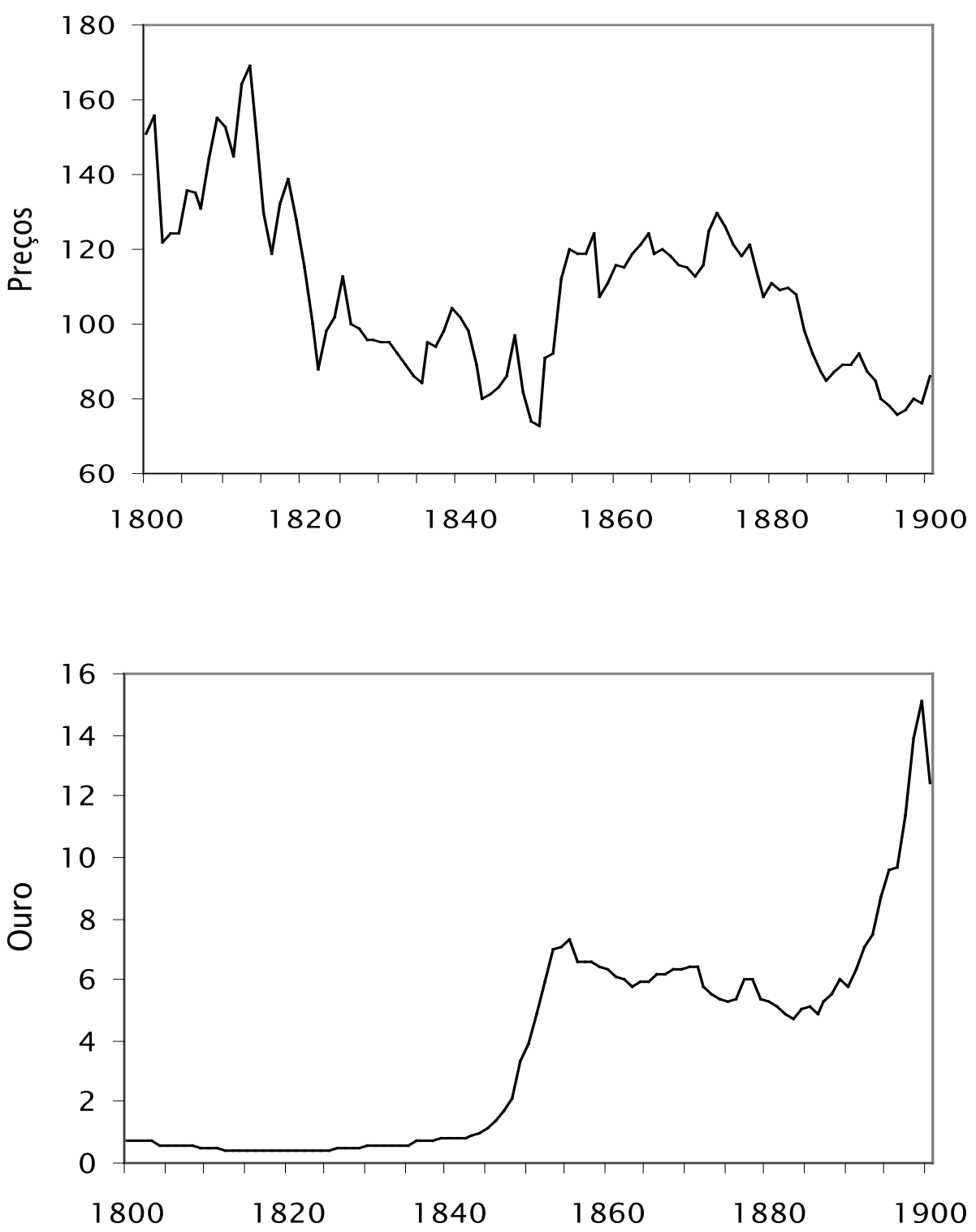

Gráfico 2 - (a) Inglaterra, preços no atacado (1913=100) e (b) Produção mundial de ouro (milhões de onças), 1800-1900

Fonte: Elaborado pelos autores a partir de Comission on the Role of Gold in the Domestic and International Monetary Systems (1982, p. 188-189) e Mitchell (1992, p. 840).

Os autores vinculados a banking school acreditavam que as emissões de notas bancárias seriam adequadamente reguladas pelas necessidades gerais do comércio, resultando impossível uma emissão excessiva. O Banco da Inglaterra, nessas condições, desempenharia apenas papel passivo, não lhe cabendo maior responsabilidade pelos estremecimentos no sistema de preços e pela frequente emergência de crises monetárias. As drenagens de suas reservas de ouro, que colocavam em perigo a conversibilidade da moeda, seriam causadas não por um desgoverno das emissões, mas por causas fortuitas que, em regra, estariam fora do controle da instituição, como guerras ou outros eventos externos. 
Segundo esse argumento, portanto, os bancos deveriam variar seus coeficientes de reserva de modo a acomodar uma maior ou menor emissão de notas, em conformidade com o nível de prosperidade do comércio em geral. Ademais, aqueles que recriminavam uma hipotética circulação monetária desmesurada promovida pelos bancos omitiam o fato de que os empréstimos adiantados aos negociantes seriam integralmente restituídos aos credores, anulando adiante seus eventuais efeitos deletérios sobre a economia (lei do refluxo). Concluíam ainda os partidários da banking school que a conversibilidade seria condição suficiente para salvaguardar a emissão de crédito e manter o balanço de pagamentos em equilíbrio no longo prazo.

Em flagrante contraste com essas posições, a currency school, de sua parte, defendia a tese de que as emissões monetárias excessivas eram responsáveis pela redução das reservas de ouro do Banco da Inglaterra e pelos consequentes pânicos financeiros que ameaçavam a livre conversibilidade. Assim, na interpretação dessa corrente, seria necessário instituir um mecanismo que, automaticamente, garantisse um sistema eficaz de flutuação metálica, ou seja, capaz de assegurar que qualquer diminuição das reservas em ouro fosse acompanhada por contração correspondente e imediata das notas bancárias.

Como desfecho prático do debate, as propostas da currency school seriam incorporadas na reforma bancária promulgada pelo governo inglês por intermédio do chamado Peel's Act, de 1844. A reforma estabeleceu, dentre outras providências, a limitação direta da capacidade de emissão de notas de crédito por parte dos bancos provinciais e, mais importante, a separação do Banco da Inglaterra em dois departamentos autônomos, o de emissão (Issue Department) e o bancário (Banking Department). Essa reforma, que reduzia os poderes discricionários da instituição, buscava alcançar o já referido sistema de flutuação metálica. Durante as duas décadas seguintes, todavia, a emergência recorrente de novas crises provaria que tais medidas não haviam sido suficientes para garantir a solidez da moeda conversível. Perante esse quadro, as controvérsias monetárias, que, por certo tempo, pareciam haver se exaurido, voltariam a ressurgir nos anos finais daquele século, já então incorporando questões como a harmonização das políticas do bancos centrais e o ajustamento externo diante de largos fluxos internacionais de capital (BORDO, 1984, p. 43-48; LAIDLER, 1991, p. 50-52).

\section{Os Antecedentes da Preferência pela Liquidez}

Após a breve revisão dos debates monetários do século XIX, pode-se retornar agora ao modelo monetário básico dos economistas clássicos. Como visto, dentre seus elementos centrais, destaca-se a ideia de neutralidade da moeda, ou seja, a percepção de constituir-se o dinheiro numa sorte de véu a recobrir o sistema econômico. Cabe então questionar-se aqui: será que, em meio aos acontecimentos monetários descritos, os autores clássicos apegaram-se, efetivamente, apenas a uma teoria da moeda neutra? De acordo com Sowell (1974, p. 56-58) e Corry (1962, p. 39-44), leitura mais cuidadosa dos escritos clássicos 
pode revelar certa contradição de ideias. Os mesmos autores que em algumas passagens apresentam a ideia da neutralidade como princípio inquestionável, noutras consideram a moeda instrumento capaz de afetar motivos e decisões dos agentes econômicos, como ilustraremos a seguir. Qual, então, a causa dessa dualidade?

Em que pese a aparente ambivalência de diversos economistas do período, a posição clássica nada tem de contraditória, desde que observado um ponto fundamental, a saber, a distinção entre proposições de curto e de longo prazo. Em condições normais, após todos os obstáculos ao livre funcionamento dos mercados haverem sido removidos, a moeda seria incapaz de exercer influência duradoura sobre as variáveis reais do sistema econômico. De forma geral, contudo, percebiase que o processo de ajustamento rumo às condições de longo prazo não seria instantâneo, implicando, muitas vezes, perturbações com efeitos transitórios sobre a economia. Esses distúrbios poderiam se originar tanto na demanda quanto na oferta de moeda. ${ }^{7}$ Pelo lado da demanda, podemos identificar em vários autores uma noção intuitiva da ideia de preferência pela liquidez que, como sabido, adquiriria contornos decisivos com Keynes no século seguinte. Já no que se refere à oferta monetária, a análise se desenvolve principalmente a partir do que ficaria conhecido como doutrina da poupança forçada, da qual se tratará adiante.

É oportuno observar aqui que, durante as primeiras décadas do século XIX, a ortodoxia clássica, congregando os defensores da Lei de Say, encontrava-se sob repetidos ataques de vozes dissidentes como Lauderdale, Malthus e Sismondi, dentre os mais notórios (veja-se BLEANEY, 1976, p. 22-78; GORDON, 1967, p. 1-43). Apontando as crises comerciais de 1815 e de 1825 como evidências tangíveis da insuficiência crônica de demanda do sistema capitalista, mantinham eles ser imprescindível certo montante de gastos improdutivos como fator de estímulo constante à produção. Isso porque, no entendimento de tais autores cépticos, uma acumulação de capital mais intensa induzida por forte apego à poupança comprometeria o indispensável balanço entre oferta crescente e consumo reduzido. O sistema econômico, por conseguinte, estaria sob permanente ameaça de estagnação devido à inevitável deflação de preços e ao estreitamento das taxas de lucro decorrentes de tal situação. Essa fundamentação das crises comerciais, por certo, não soava convincente aos ouvidos de Say, Ricardo ou Stuart Mill. Replicavam eles, de maneira peremptória, consistir a acumulação de capital em nada além da mera contratação de trabalhadores produtivos, cujo consumo efetivo cresceria na mesma proporção do emprego. ${ }^{8}$

7 Tal distinção corresponde àquela estabelecida por Becker e Baumol (1962) (veja-se também PATINKIN, 1965, 193-195) entre "Identidade" versus "Igualdade" de Say. Essa última estaria associada ao fato de o equilíbrio agregado entre oferta e demanda e, portanto, também no mercado monetário, na visão dos clássicos, ser mais bem entendido como resultado de um processo de correções sucessivas de desajustes e desproporções transitórias em vez de um axioma de validade universal, como assumido na primeira interpretação da Lei dos Mercados. Já para Hicks (1957), tais perturbações, decorrentes de certa rigidez nos rendimentos nominais, fariam com que o universo clássico estrito, com neutralidade da moeda e produto fixo, fosse válido apenas a partir do pleno emprego ou então em condições de crises agudas de desemprego nas quais os salários se tornassem completamente maleáveis.

8 A respeito do debate sobre a saturação geral dos mercados nos anos de 1820 na Inglaterra, consulte-se Malthus (1983, caps. V-VII), com as respectivas notas de Ricardo (1983), bem como Sowell (1963) e Cottrell (1997). 
A principal deficiência na análise dos dissidentes, entretanto, a despeito de sua visão aguçada das falhas de mercado do capitalismo, residia na desconsideração quase absoluta dos problemas inerentes à própria existência da moeda numa economia de trocas. Diante desse silêncio dos críticos, seriam os economistas clássicos ortodoxos, como Say, Thornton e Stuart Mill (sobre as teorias monetárias de tais autores, veja-se ANDRADE; LOPES, 1989; BÉRAUD, 2003), os que viriam a considerar de forma mais séria a possibilidade de ser a moeda retida por suas outras propriedades que não aquelas ligadas à sua função de elemento facilitador das trocas. Segundo esses economistas, o público poderia ocasionalmente decidir entesourar, ou seja, reter dinheiro, não com o intuito de ampliar suas transações cotidianas, mas, sim, de se resguardar diante de expectativas desfavoráveis acerca das condições futuras dos negócios. $\mathrm{O}$ entesouramento descrito, contudo, tenderia a gerar oscilações nas variáveis reais da economia, criando insuficiência temporária de demanda agregada em relação à oferta. Admitia-se aí, portanto, uma forma particular de não neutralidade da moeda, embora no contexto de uma transgressão passageira da Lei de Say (CORRY, 1962, p. 96-108; SOWELL, 1974, p. 61-63).

Um dos representantes mais conspícuos da interpretação monetária das crises comerciais no campo da ortodoxia clássica foi Henry Thornton. No livro An enquiry into the nature and effects of the paper credit of Great Britain (1802), ele critica a noção de quantidade ótima de moeda tal como defendida por Adam Smith e pelos quantitativistas radicais. Primeiramente, Thornton ressalta que, em vista do pagamento ou não de juros, os diferentes componentes do meio circulante apresentariam velocidades distintas de circulação. Além disso, haveria de se levar em conta a circunstância de que a própria velocidade de circulação dos diferentes componentes do meio circulante poderia ser modificada em conformidade com as expectativas dos agentes econômicos em relação ao estado geral dos negócios. Como esclarece o próprio Thornton a propósito das notas bancárias:

As causas que levam a uma variação na rapidez de circulação das notas bancárias podem ser variadas. Em geral, cabe observar que um estado de confiança elevada trabalha para acelerar a circulação das mesmas. [...] Um estado de otimismo contribui para que os indivíduos resguardem-se menos prudentemente contra contingências. [...] Quando, ao contrário, a estação de desconfiança se instala, a cautela sugere que a perda de juros devida a uma retenção das notas por alguns dias adicionais seja desconsiderada. (THORNTON, 1991, p. 96-97).

Importante aspecto na análise proposta por esse autor, incorporada pela banking school em sua oposição ao argumento da existência de um nível ótimo de preços na economia (que resultaria independente da composição do meio circulante), reside, como indicado, na percepção de que os vários componentes da oferta monetária possuiriam diferentes velocidades de circulação para um dado estado das expectativas. Em termos mais precisos, essa distinção se apresentava em função do pagamento ou não de juros, guardando a velocidade 
de circulação de cada meio de pagamento relação inversa com sua respectiva remuneração.

A possibilidade de a demanda por moeda manter conexão com o quadro geral das expectativas já havia sido contemplada, anteriormente, pelo próprio Say ao elencar os vários obstáculos à ação eficaz da concorrência tais como as guerras, os embargos comerciais, as dificuldades de comunicação e de transporte, os tributos arbitrários e, por fim, mas não memos importante, a especulação:

É lenta [a circulação de bens] numa época de agiotagem, quando as variações súbitas ocasionadas pelo jogo sobre as mercadorias fazem com que algumas pessoas esperem um benefício baseado numa simples variação nos preços. A mercadoria fica, então, à espreita de uma alta e o dinheiro à espreita de uma baixa; das duas partes, temos capitais ociosos, inúteis para a produção. (SAY, 1985, p. 146).

No início da década de 1820, ao redigir seus Essays on some unsettled questions on political economy (publicados somente em 1844), o jovem Mill já reprovava, de forma categórica, os autores que denunciavam a tendência do capitalismo a um investimento excessivo e, em razão disso, prescreviam a necessidade de se estimular o consumo como remédio para a superabundância geral de mercadorias. Alguns parágrafos adiante, contudo, o próprio Mill admitiria também que a rápida emissão de dinheiro poderia fazer eclodir processos especulativos agudos que acabariam por desembocar em severa crise comercial quando os agentes se dessem conta, finalmente, de estarem auferindo seus rendimentos em moeda depreciada (MILL, 2000, p. 37-55). Nesses momentos, a interveniência do dinheiro no processo de trocas revelaria todo seu poder de ruptura das operações tradicionais de comércio. Ou, nos termos de Mill:

Os atos de compra e venda estando assim separados, pode muito bem ocorrer em certa ocasião uma ampla inclinação a vender sem demora, acompanhada por uma inclinação igualmente geral em postergar ao máximo possível todas as compras. Esse, com efeito, é sempre o caso durante aqueles períodos descritos como de excesso geral. (MILL, 2000, p. 52-53).

Já nos Princípios (1848), Mill oferece tratamento mais elaborado da preferência pela liquidez, articulado no contexto geral dos ciclos especulativos de crédito. Durante as fases de expansão da economia, escreve ele, prevaleceriam expectativas convergentes por parte de banqueiros e tomadores de empréstimos. Esses últimos estariam motivados a fazer uso de todo o crédito disponível diante das perspectivas de ganhos especulativos originados na antecipação de algum choque exógeno, como a abertura de novos mercados externos, a descoberta de fontes alternativas de matérias-primas etc. As previsões otimistas dos empreendedores e a maior liberalidade nos empréstimos por parte dos banqueiros desaguariam numa situação de excesso de liquidez na economia, caracterizada por expectativas de ganhos ascendentes e elevação dos preços. Em condições específicas de opinião coletiva, observa Mill ao discorrer sobre os efeitos do crédito, 
[...] tais exemplos de aumento rápido da fortuna despertam imitadores numerosos, e a especulação não somente vai muito além do que é justificado pelos motivos iniciais para esperar aumento de preço, senão que estende a artigos nos quais nunca houve tais motivos para esperar aumento de preço [...]. Em tais períodos ocorre grande ampliação do crédito. (MILL, 1996, p. 103).

A certa altura da maré montante especulativa, todavia, os homens de negócios mais experimentados perceberiam que a continuidade do estado vigente de coisas não seria sustentável em vista do descolamento excessivo dos preços de seus respectivos valores. Ao se adiantarem ao processo de reversão da trajetória expansiva por meio do barateamento de suas mercadorias, eles lançariam a economia na fase descendente do ciclo, marcada agora pela liquidação generalizada nos preços. Os interesses dos banqueiros e dos tomadores de empréstimos, nesse ponto, haveriam se tornado conflitantes. $\mathrm{O}$ crédito encolheria, os preços desabariam e as condições de lucratividade revelarse-iam cada vez mais restritivas. Nesse cenário, sobreviria inevitavelmente a crise comercial e, em meio à consequente atmosfera de queda nas vendas, de falências e de retração nos negócios, os indivíduos passariam a apresentar comportamento preventivo de preferência pela liquidez:

Pelo fato de todos os comerciantes terem compromissos a pagar, e pelo fato de ninguém sentir segurança de poder dispor, no momento certo, da porção de recursos que emprestou a outrem, ninguém gosta de desfazerse do dinheiro de que dispõe, ou de adiar a cobrança do direito a ele. A essas considerações racionais soma-se, em casos extremos, um estado de pânico, tão irracional quanto a confiança excessiva anterior; toma-se dinheiro emprestado para curto prazo, pagando praticamente qualquer taxa de juros, procurando-se a qualquer custo vender mercadorias com pagamento a vista. (MILL, 1996, p. 104).

Cabe notar ainda que a opção pela posse de liquidez tenderia, de acordo com Mill, a exacerbar ainda mais a gravidade da crise comercial, porquanto a retenção de moeda terminaria por se traduzir numa insuficiência temporária da demanda em relação à produção disponível. Isso, porém, teria lugar unicamente em virtude da retração indiscriminada no crédito nos momentos de colapso comercial, a qual atingiria até mesmo os indivíduos e firmas solváveis com sólida reputação nos meios financeiros (para a teoria dos ciclos dos negócios de Stuart Mill, veja-se o próprio MILL, 1996, p. 99-139 e FORGET, 1990). Dessa forma, os economistas alinhados com a Lei de Say lograram oferecer uma explicação das crises econômicas alicerçada na especulação alimentada pelo crédito bancário, sem concessões às propostas de ampliação das despesas improdutivas dos proprietários de terras ou do governo, como postulavam incansavelmente os autores dissidentes. Se para esses últimos o problema nascia de uma tibieza latente da procura agregada, na teoria dos economistas ortodoxos, em particular Stuart Mill, o problema afloraria pela razão inversa, como desfecho de um 
excesso incontido de demanda a desaguar numa comoção comercial marcada por escassez de crédito. Mas, se pelo lado da procura a preferência pela liquidez era uma via a partir da qual os clássicos admitiam a hipótese de não neutralidade da moeda, mesmo restrita ao curto prazo, pelo lado da oferta essa possibilidade seria vislumbrada, sobretudo, mediante a teoria da poupança forçada, da qual se tratará a seguir.

\section{Moeda e Poupança Forçada}

Retomando o modelo clássico básico, o volume de produção da economia seria definido a partir de condições estritamente reais, ou seja, da quantidade de fatores de produção, do grau de especialização do trabalho e da intensidade da acumulação de capital. Alterações no produto só poderiam ser obtidas a partir da variação de pelo menos um desses fatores e, no longo prazo, nada teriam a ver com a quantidade de moeda. Como fenômeno de curto prazo, contudo, reconhecia-se a possibilidade de que alterações na oferta monetária pudessem provocar perturbações no nível de atividade da economia. Isso ocorreria a partir de efeitos distributivos induzidos por oscilações nos preços não devidamente acompanhadas por reajustes equivalentes em certas categorias de rendimentos.

Say, por exemplo, acusa de falsários armados os príncipes e reis franceses que, ao longo do tempo, manipularam o conteúdo em metal das moedas em circulação: "O mal produzido foi de tal ordem que, em várias épocas de nossa história, as operações monetárias afugentaram completamente qualquer espécie de comércio" (SAY, 1985, p. 231). De resto, recrimina ele sem rodeios o recurso a tal expediente vergonhoso por favorecer os devedores a expensas dos credores (poupadores), em nítido prejuízo à acumulação de capital:

O efeito imediato da alteração das moedas é uma redução das dívidas e das obrigações pagáveis em moeda, das rendas perpétuas ou reembolsáveis, pagáveis pelo Estado ou pelas pessoas particulares, dos salários e pensões, dos aluguéis e arrendamentos, de todos os valores, enfim, que se exprimam em moeda. Tal redução faz com que o devedor ganhe e com que o credor perca [...]. Não se empresta de bom grado quando se está sujeito a receber menos do que se emprestou e dificilmente se toma emprestado quando se está sujeito a devolver mais do que se recebeu. Os capitais não conseguem, por conseguinte, encontrar emprego produtivo. (SAY, 1985, p. 232-233).

De modo geral, contudo, os economistas clássicos, particularmente na Inglaterra, tinham em mente um fenômeno em presença do qual a expansão da oferta monetária não implicaria retardo, mas, sim, avanço na acumulação de capital mediante processo que denominavam "poupança forçada" (forced saving). Em presença de majoração do nível de preços deflagrada por incremento na disponibilidade de dinheiro, existiriam classes sociais cujos 
rendimentos seriam relativamente fixos ou reajustados apenas com certa defasagem em relação aos preços. Em decorrência disso, a inflação provocaria transferência de recursos dessas categorias para os indivíduos de posse do "novo" dinheiro. Mas, em prol de quem, especificamente, tais recursos seriam transferidos? Para os autores clássicos, os beneficiários comporiam as classes acumuladoras da economia, isto é, os empresários capitalistas cujos rendimentos não seriam fixos e que, amiúde, estariam de posse do dinheiro adicional em razão de sua facilidade de acesso ao crédito. Esses empresários utilizariam os recursos assim obtidos, via redução forçada no consumo de outros, na incorporação de novos trabalhadores ao processo produtivo.

A ideia não era, a rigor, inédita, tendo sido anteriormente intuída por Cantillon (1755) quando se contrapôs a Locke no tocante à repercussão de um aumento na produção de ouro. Em tais circunstâncias, afirmava o primeiro, o consumo dos mineiros e dos proprietários das minas aumentaria, causando então elevação dos preços, dos lucros e, posteriormente, da oferta de artigos como carne, vinho e cerveja: "Aqueles, portanto, que sofrerão com essa carestia e com o consumo crescente serão, primeiramente, os proprietários de terras, durante o termo de seus arrendamentos, bem como seus servos e todos os trabalhadores ou pessoas trabalhando com salários fixos" (CANTILLON, 1965, p. 265). Aqui, no entanto, a questão envolvia ainda apenas redistribuição do consumo. Pouco antes, Hume, no ensaio Of money (1752), já contemplara a possibilidade distinta de um acréscimo no estoque de metais preciosos vir a animar o investimento nas atividades produtivas durante o processo de elevação dos preços:

Quando qualquer quantidade de moeda é importada na nação, ela não é logo dispersa entre muitas mãos, mas se confina aos cofres de poucas pessoas, que imediatamente buscam aplicá-la com vantagem. [...] Eles são, por essa via, habilitados a empregar mais trabalhadores do que antes, os quais nem sonham em demandar maiores salários por estarem satisfeitos com a ocupação fornecida por seus patrões. [...] É fácil rastrear o dinheiro em seu progresso por todo o reino; encontraremos que ele primeiro intensifica a diligência de cada indivíduo antes de aumentar o preço do trabalho. (HUME, 1985, p. 286-287).

É interessante que a ideia de poupança forçada associada à inflação viesse a ganhar destaque na Inglaterra no século seguinte, precisamente durante o período deflacionário anterior à retomada da conversibilidade da libra esterlina em 1821. Mas isso não deve causar estranheza ao se considerarem as propostas dos economistas de Birmingham, especialmente as de Thomas Attwood, banqueiro, parlamentar e defensor de ampla reforma nas instituições monetárias do país (veja-se CHECKLAND, 1948; HUMPHREY, 2003, p. 15-17; LINK, 1959, p. 6-35). Para Attwood, os problemas de deflação e desemprego da economia britânica após a crise de 1815 radicavam-se na escassez de meio circulante provocada pela política de austeridade fiscal e monetária voltada à restauração da conversibilidade da libra à paridade do pré-guerra. O remédio para tais 
dificuldades, na sua maneira de ver, residia na ampliação da oferta de dinheiro a fim de estimular a demanda e a confiança dos investidores por meio da elevação dos preços, o que redundaria numa retomada da produção e do emprego, ainda que ao custo ulterior de abandono definitivo do padrão-ouro:

Os preços da propriedade sendo aumentado pelo acréscimo na circulação, um prêmio é obtido na produção de cada artigo da indústria e esse prêmio conduz o trabalho ao pleno-emprego. As forças produtivas do país sendo assim utilizadas ao máximo, uma grande massa de riqueza anual será então produzida e no próprio ato dessa produção o consumo dessa massa adicional de mercadorias é realizado, seja na forma de salários, de lucros ou de impostos. (ATTWOOD, 1832 apud LINK, 1959, p. 26).

De certa forma, Attwood e outros críticos da restauração, bem como os dissidentes da ortodoxia clássica, apoiavam-se na prosperidade do tempo de guerra, acompanhada por um salto na emissão monetária, na inflação e nos déficits públicos, como evidência factual de suas teses de necessidade de reforço permanente da demanda como fator de viabilidade do desenvolvimento capitalista. É compreensível também que esse mesmo assunto já tivesse recebido a atenção de outros autores dissidentes, como nos primeiros escritos de Malthus, particularmente em um artigo para a Edinburgh Review, publicado em 1811 , onde consta a seguinte passagem: "Se tal distribuição do meio circulante tivesse lugar de modo a deixar o comando da produção do país principalmente nas mãos das classes produtivas, isto é, fazendeiros, manufatores e comerciantes [...] a proporção entre capital e rendimentos seria profundamente alterada em favor do capital" (MALTHUS apud HAYEK, 1933, p. 127).

As críticas dos reformistas monetários, aliadas à experiência histórica, não deixariam de influenciar até mesmo os economistas mais renitentes na defesa do padrão-ouro. As propostas de flexibilização da oferta monetária apresentadas na primeira metade do século XIX na Inglaterra, embora reconhecidas como capazes de estimular a produção, eram, não obstante, rebatidas pelos políticos e economistas ortodoxos sob três argumentos, muitas vezes invocados conjuntamente. Em primeiro lugar, embora com menor frequência, mediante a negação liminar de existência da poupança forçada, porquanto se a inflação significava reajustes de todos os preços, como assegurava a Teoria Quantitativa, assim também deveria ocorrer, cedo ou tarde, com os rendimentos. Atitude mais comum, no entanto, consistia na admissão do fenômeno, mas concedendolhe caráter meramente transitório. Em segundo lugar, contrapunha-se que a liberalidade monetária e a consequente elevação dos preços internos comprometeriam o saldo comercial do país, causando evasão de espécie e o colapso do padrão-ouro. Em conexão com isso, dizia-se, não haveria como garantir o correto manejo de uma moeda inconversível por parte dos governos, que facilmente seriam seduzidos a extrapolar os limites adequados de emissão com resultados funestos sobre a economia. Por fim, em terceiro lugar, expressava a ideia de que a poupança forçada, ainda que admitida como benéfica à acumulação de capital, deveria ser considerada uma forma 
fraudulenta e imoral de angariar recursos adicionais para a promoção da prosperidade econômica, consistindo num expediente a ser repudiado por todos os cidadãos de bem.

A primeira linha de defesa do padrão-ouro seria aquela adotada por Ricardo que, avesso à análise de curto prazo, em suas manifestações públicas simplesmente negava importância à poupança forçada. Em depoimento a um Comitê dos Lordes, em 1819, indagado sobre as implicações de uma emissão desmesurada de dinheiro sobre a agricultura, as manufaturas e o comércio, respondeu de pronto: "Sob certas circunstâncias, isso pode perturbar as proporções em que o produto do capital se divide entre o capitalista e o trabalhador, mas em geral [...], penso eu, isso nunca aumenta o produto do capital" (RICARDO, 1962, p. 288). Reservadamente, no entanto, em carta a James Mill, no ano de 1811, já havia ele reconhecido a existência de efeitos positivos da inflação sobre a acumulação de capital, mas conferindo-lhes eficácia tão somente provisória. Afinal, ninguém melhor do que Ricardo para ter presente a clássica lei férrea dos salários a impedir um rebaixamento duradouro dos ganhos dos trabalhadores aquém do mínimo de subsistência. Ou, conforme o trecho a seguir de sua correspondência:

\begin{abstract}
A meu juízo, existe somente uma maneira de acrescer o capital de um país como conseqüência de um incremento no dinheiro; seria o seguinte. Até o momento em que os salários da mão-de-obra tenham encontrado seu novo nível com o valor alterado do dinheiro, a situação do trabalhador pioraria, em termos relativos; produziria relativamente mais do que consome ou, melhor dito, estaria obrigado a consumir menos. O manufatureiro poderia empregar uma quantidade maior de mão-de-obra, já que receberia um preço adicional por sua mercadoria; em conseqüência, poderia aumentar seu capital real até que a alta de salários da mão de obra o colocasse em nível adequado. (RICARDO, 1962, p. 11, grifo nosso).
\end{abstract}

A segunda linha de ataque ao conceito de poupança forçada seria adotada por Stuart Mill. Ao comentar as propriedades do crédito, ele reconhece a ocorrência do fenômeno, mas sob condições específicas: "Normalmente, as notas bancárias adicionais são primeiro emitidas para produtores e comerciantes, para serem empregadas como capital", explica Mill, complementando a seguir que "[...] uma parte maior desse estoque, na mesma medida daquilo que teria sido consumido improdutivamente, é aplicada à produção, sendo aí um aumento real de capital" (MILL, 1996, p. 88,). Adiante, entretanto, ao dissertar sobre a moeda inconversível, ele não poupa adjetivos ao desqualificar as propostas dos reformistas, particularmente as de Attwood. $\mathrm{O}$ abandono do lastro em outro, adverte Mill, além de beneficiar injustamente os devedores com obrigações nominais fixas e fomentar a especulação em prejuízo da coletividade num ambiente inflacionário, exigiria regras rígidas e complexas de administração do estoque de moeda extremamente difíceis de serem implementadas: "E tão grande a tentação de emitir em excesso, em determinadas emergências financeiras, que não se admite nada que possa 
tender, no menor grau que seja, a abrandar os obstáculos que limitam tal emissão excessiva" (MILL, 1996, p. 123).

Por fim, Jeremy Bentham, Thornton, Ricardo e o próprio Stuart Mill recorreriam, igualmente, à censura incondicional da poupança forçada por representar a mesma redistribuição injusta do produto, obtida por meio de artifício monetário envolvendo um confisco indevido sobre os indivíduos com rendimentos fixos, principalmente os assalariados. Assim, Bentham, um dos pioneiros da noção de "frugalidade forçada", quando debate as iniciativas a serem excluídas da agenda do governo, afirma diretamente que o aumento na oferta de dinheiro representaria um imposto sobre os possuidores de rendimentos fixos em favor dos produtores, de sorte que "[...] a riqueza é aumentada a expensas do conforto e da justiça nacional" (BENTHAM apud HAYEK, 1933, p. 124). Thornton, por sua vez, assume que certa emissão de papel-moeda poderia trazer algum estímulo à indústria, mas com a ressalva de que tal poupança adicional "[...] seria obtida com sacrifício e injustiça proporcionais" (THORNTON, 1991, p. 239). Nesse ponto, Ricardo, novamente, é mais incisivo ao reprovar a sugestão de certos comentaristas de seu opúsculo High price of bullion (1810) que haviam insinuado a existência de vantagens associadas a uma expansão do meio circulante por transferir-se assim poder de compra dos consumidores para os produtores. Com efeito, responde Ricardo, os detentores de rendas fixas, na medida em que já consumissem menos do que ganhavam, teriam sua poupança voluntária reduzida, de sorte que o prêmio sobre o capital poupado seria injustamente transferido deles para os banqueiros que promovessem o crescimento da disponibilidade monetária:

De qualquer forma, o mal é certo. Ele será acompanhado por um grau de injustiça para com os indivíduos que necessita apenas ser devidamente entendido para motivar a censura e a indignação de todos aqueles que não sejam por completo indiferentes aos sentimentos de honradez. (RICARDO, 2005, Apêndice).

Stuart Mill, anos depois, não se revelaria menos eloquente em sua condenação absoluta da poupança forçada, em que pese reconhecer a economia de recursos advinda do uso de papel-moeda, ao invés de ouro, como substrato da circulação:

Não há meio de um aumento geral e permanente dos preços ou, em outras palavras, uma depreciação do dinheiro, beneficiar quem quer que seja, a não ser a custa de outrem. A substituição do dinheiro metálico por papel moeda é um ganho para a nação, mas qualquer aumento do papelmoeda além desse limite não passa de uma forma de roubo. (MILL, 1996, v. II, p. 127).

De qualquer modo, os debates sobre reformas monetárias e eventuais benefícios da inflação num sistema de moeda inconversível perderiam muito de seu ímpeto na Inglaterra após as descobertas de ouro na Austrália e na 
Califórnia na metade do século XIX (ver Gráfico 2). O alívio na escassez monetária propiciaria, durante algum tempo, a retomada de uma trajetória ascendente para os preços mesmo sob o sistema de moeda conversível. Somente com a chegada da Grande Depressão do século XIX, iniciada em 1875 e que se estenderia pelas duas décadas seguintes, as questões relativas ao adequado suprimento de moeda na economia voltariam à ordem do dia, tema que, contudo, escapa aos limites deste trabalho.

\section{Considerações Finais}

Do que foi exposto nas páginas anteriores, resulta evidente a dificuldade de enquadramento, numa única matriz teórica, das concepções dos autores clássicos relativas ao papel da moeda no sistema de produção capitalista. Se, com efeito, a existência de uma clivagem entre as esferas real e monetária da economia se afigurava uma forma de interpretação da realidade esposada pela quase totalidade dos principais nomes do período clássico, é também verdadeiro que as exceções a tal norma não deixavam de ser por eles largamente discutidas e, até mesmo, aceitas. Mas isso, é imperativo observar, não significa que, do ponto de vista da ortodoxia clássica, as posições até certo ponto flexíveis de Say, Thornton e Stuart Mill no que tange ao reconhecimento da existência da procura por liquidez ou da poupança forçada expressassem algum tipo de incoerência mais profunda. Pois, em última análise, como visto, a forma como esses fenômenos foram por eles interpretados em nenhum momento chegou a distanciá-los de suas posições mais irredutíveis. Noutros termos, as possibilidades de não neutralidade da moeda por eles contempladas não continham implicações teóricas de monta no tocante a duas visões da realidade da época que lhes eram essenciais: (i) a capacidade de o sistema econômico capitalista gerar sua própria demanda, de onde o repúdio incondicional aos gastos improdutivos e (ii) a defesa irrestrita do regime de conversibilidade ouro como a melhor garantia de um padrão monetário menos afeito às flutuações e à interferência lesiva do poder público.

\section{Referências}

ANDRADE, J. P.; LOPES, C. M. Moeda e crédito: a versão "clássica" de Thornton e Mill. In: AMADEO, E. (Org.). Ensaios sobre economia política moderna: teoria e história do pensamento econômico. São Paulo: Marco Zero, 1989. p. 69-86.

BARRO, R. J. Money and the price level under the gold standard. In: EICHENGREEN, B. (Org.). The gold standard in theory and history. New York: Methuen, 1985. p. 81-99.

BECKER, G.; BAUMOL, W. The classical monetary theory: the outcome of the discussion. In: SPENGLER, J. J.; ALLEN, W. R. (Org.). Essays in economic thought: Aristotle to Marshall. Chicago: Rand McNally, 1962. p. 753-771. 
BÉRAUD, A. Jean-Baptiste Say et la theorie quantitative de la monnaie. 2003. Disponível em: <http://econpapers.repec.org/>. Acesso em: 2 out. 2009.

BLEANEY, M. Underconsumption theories: a history and critical analysis. New York: International Publishers, 1976.

BORDO, M. The gold standard. The traditional approach. In: BORDO, M.; SCHWARTZ, A. J. (Org.). A retrospective on the classical gold standard, 1821-1931. Chicago: The University of Chicago Press; NBER, 1984. p. 23-112.

CANTILLON, R. Essai sur le commerce en général. In: MONROE, A. E. (Org.). Early economic thought: selections from economic literature prior to Adam Smith. Cambridge: Harvard University Press, 1965. p. 247-277.

CHECKLAND, S. G. The Birmingham economists 1815-1850. The Economic History Review, v. 1, n. 1, p. 1-19, 1948.

COMISSION ON THE ROLE OF GOLD IN THE DOMESTIC AND INTERNATIONAL MONETARY SYSTEMS. Report to the Congress. Washington: Government Printing Office, Mar. 1982. V. 1.

CORRY, B. A. Money, saving and investment in English economics 1800-1850. New York: St. Martin's Press, 1962.

COTTRELL, A. Keynes, Ricardo, Malthus and Say's Law. In: History of Economics Society Meeting, Charleston, South Carolina, June 1997.

FETTER, F. W. The development of British monetary orthodoxy 1797-1875. Cambridge: Harvard University Press, 1965.

FORGET, L. John Stuart Mill's business cycles. History of Political Economy, v. 22, n. 4, p. 629642, 1990.

GORDON, B. Non-Ricardian political economy: five neglected contributions. Boston: Harvard University Printing Office, 1967.

HAYEK, F. A note on the development of the doctrine of "forced saving". Quarterly Journal of Economics, v. 47, p. 123-133, 1933.

HEGELAND, $\mathrm{H}$. The quantity theory of money: a critical study and interpretation and a restatement. New York: Augustus M. Kelley, 1969.

HICKS, J. A rehabilitation of "classical" economics. The Economic Journal, v. 67, n. 266, p. 278289, June 1957.

HOLLANDER, J. The development of the theory of money from Adam Smith to David Ricardo. Quarterly Journal of Economics, Cambridge, v. 25, p. 429-470, 1910.

HUME, D. Essays, moral, political and literary. Liberty Fund: Indianapolis, 1985.

HUMPHREY, T. M. Classical deflation theory. Federal Reserve Bank of Richmond, Nov. 2003. (Working Paper 03-13). 
HYNDMAN, H. M. Commercial crises of the nineteenth century. New York: Augustus M. Kelley, 1967.

LAIDLER, D. The golden age of the quantity theory. Princeton: Princeton University Press, 1991.

LINK, R. G. English theories of economic fluctuations 1815-1848. New York: Columbia University Press, 1959.

MALTHUS, T. R. Princípios de Economia Política. São Paulo: Abril Cultural, 1983.

MigLIOLI, J. Acumulação de capital e demanda efetiva. São Paulo: T. A. Queiroz, 1982.

MILL, J. S. Essays on some unsettled questions of political economy. Kitchener: Batoche Books, 2000.

Princípios de Economia Política: com algumas de suas aplicações à filosofia social. São Paulo: Nova Cultural, 1996. v. II.

MINTS, L. A history of banking theory in Great Britain and the United States. Chicago: The University of Chicago Press, 1945.

MITCHELL, B. R. International historical statistics 1750-1988. New York: Stockton, 1992.

NIEBYL, K. H. Studies in the classical theories of money. New York: Columbia University Press, 1948.

O’BRIEN, D. P. Los economistas clásicos. Madrid: Alianza Editorial, 1975.

PATINKIN, D. Money, interest and prices. New York: Harper and Row, 1965.

RICARDO, D. Actas de declaraciones prestadas ante las Comisiones de la Cámara de los Lores, Die Veneris, $26^{\circ}$ Martii 1819. In: SRAFFA, P. (Org.). Obras y correspondência de David Ricardo. México: Fondo de Cultura Económica, 1962. v. V.

. Carta a James Mill, $1^{\circ}$ de janeiro de 1811. In: SRAFFA, P. (Org.). Obras y correspondência de David Ricardo. México, Fondo de Cultura Económica, v. VI, 1962.

. Notas aos Princípios de economia política de Malthus. São Paulo: Abril Cultural, 1983.

. Princípios de economia política e tributação. São Paulo: Nova Cultural, 1996.

. The high price of bullion, a proof of the depreciation of bank notes. London: John Murray, 1810. Disponível em: <http://phare.univ-paris1.fr/>. Acesso em: 19 nov. 2005.

ROBBINS, L. The theory of economic policy in English classical political economy. London: Macmillan, 1961.

ROCKOFF, $\mathrm{H}$. Some evidence on the real price of gold, its cost of production, and commodity prices. In: BORDO, M.; SCHWARTZ, A. J. (Org.). A retrospective on the classical gold standard, 1821-1931. Chicago: The University of Chicago Press; NBER, 1984. p. 613-644.

SAY, J.-B. Tratado de economia política. São Paulo: Abril Cultural, 1983.

SAYERS, R. Ricardo's views on monetary questions. The Quarterly Journal of Economics, v. 67, n. 1, p. 30-49, Feb. 1953. 
SMITH, A. A riqueza das nações: investigação sobre sua natureza e suas causas. São Paulo: Nova Cultural, 1996. v. I.

SOWELL, T. Classical economics reconsidered. Princeton: Princeton University Press, 1974. 203, Nov. 1963.

The general glut controversy reconsidered. Oxford Economic Papers, v. 15, n. 3, p. 193-

THORNTON, H. An enquiry into the nature and effects of the paper credit of Great Britain. London: Allen E Unwin, 1991.

VINER, J. Studies in the theory of international trade. New York: Harper and Brothers, 1937.

Recebido em: 18/05/2010.

Aceito em: 09/11/2010. 